\title{
São Paulo em
}

Super 8

\section{[ ENTREVISTA ]}

\section{Rafael Cruz}

Especial para a Revista Extraprensa 


\section{[ RESUMO ABSTRACT RESUMEN]}

Consolidado como importante espaço de difusão artístico e cultural e precursor da produção audiovisual em Super 8mm na cidade de São Paulo nas décadas de 70 e 80, o Grupo de Realizadores Independentes de Filmes Experimentais, o GRIFE, foi fruto do encontro da historiadora Maria Luiza de Alencar com o cineasta Abrão Berman. Malu, co-fundadora do grupo, relata sua experiência no ensino e produção com a nova bitola.

Palavras-chaves:Cinemaindependente. Cinema experimental.Super 8mm. Audiovisual.

Established as an important artistic and cultural diffusion space and precursor of audiovisual production in Super $8 \mathrm{~mm}$ in São Paulo in the 70s and 80s, the Group of Independent Directors of Experimental Films, the GRIFE, was the result of a colaboration between the historian Maria Luiza Alencar and the film-maker Abrão Berman. Malu, the co -founder of the group, describes her experience in teaching and producing with the new support.

Keywords: Independent film. Experimental film. Super 8mm. Audiovisual.

Consolidado como importante espacio de difusión artístico y cultural y precursor de la producción audiovisual en Super $8 \mathrm{~mm}$ en la ciudad de São Paulo en las décadas de 70 y 80, el Grupo de Realizadores Independientes de Películas Experimentales, el GRIFE, surgió tras el encuentro de la historiadora Maria Luiza de Alencar con el cineasta Abrão Berman. Malu, cofundadora del grupo, relata su experiencia en la enseñanza y producción con el nuevo soporte.

Palabras clave: Cine independiente. Cine experimental. Super 8mm. Audiovisual. 
paulista durante seis anos e que serviu como importante vitrine para a difusão superoitista, desde as produções aclamadas até as mais experimentais.

No âmbito comercial destacou-se a produção de peças publicitárias para clientes como Philips, Olivetti, Estrela, Embraer, Arno, DPZ, Colgate, Nestlé, Delta, Ford, Avibras e General Motors.

Malu se afasta do grupo em 1976 para organizar a produtora de comerciais em VT da TV Globo de São Paulo, que mais tarde recebeu a denominação de GLOBOTEC.

As atividades do GRIFE seguiram até 1981 com Berman. Suas produções hoje compõem o acervo do Museu da Imagem e Som de São Paulo, o MIS.

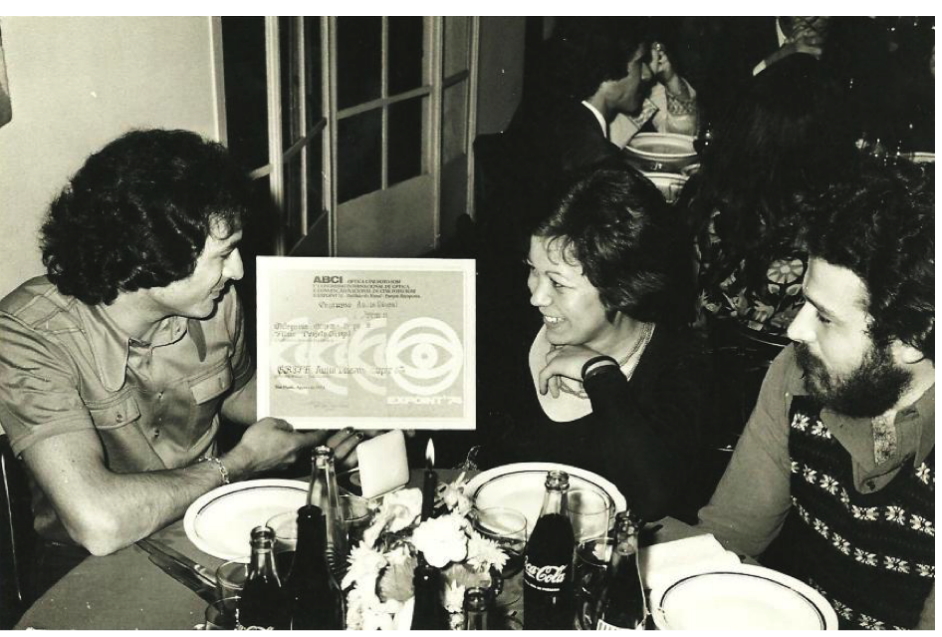

Imagem 2 - Abrão Berman (esquerda) e Malu Alencar (centro).

Fonte: Divulgação - Acervo pessoal da entrevistada.
Rafael Cruz: Lançado no mercado em 1965 pela Kodak, o Super 8mm foi notável pela adesão do público à esta tecnologia, mesmo o não profissional. Toda nova tecnologia audiovisual traz consigo mudanças significativas na produção, como o advento dos smartphones, quando se passou a ser possível a realização de vídeos curtos em qualquer lugar, por qualquer pessoa. Qual a importância de se fornecer ao público este tipo de tecnologia, neste grau de acessibilidade?

Malu Alencar: $\bigcirc$ Super $8 \mathrm{~mm}$ foi revolucionário, pois possibilitou a realização de registros familiares, viagens e outros através do filme, uma tecnologia até então restrita à profissionais da área, abrindo um leque para amadores criarem e se realizarem como "artistas". O Super 8mm foi o "start" para uma nova era da tecnologia da informação: video, internet, celular e toda toda mudança que assistimos hoje com as novas mídias.

Rafael Cruz: $\bigcirc$ GRIFE atuou como fórum de discussão de ideias, que iam além do vídeo. Algumas edições dos Super Festivais promovidos pelo GRIFE entre 1973 e 1983 contaram com um seminário de estudos e debates sobre cinema Super $8 \mathrm{~mm}$ e com a escola de formação, que além da técnica explorava aspectos narrativos e temáticos. Qual foi a expectativa e a avaliação do GRIFE em ir além da técnica?

Malu Alencar: $\bigcirc$ GRIFE foi um daqueles acertos inexplicáveis que o acaso nos possibilitou. Abrão Berman apaixonado por cinema fez cursos no Institut de Hautes Études Cinématographiques na França no final de 1960 e foi em Paris que começou a realizar filmes experimentais e curtas. Eu tinha saído da História/USP, estava fazendo um curso na ESPM e trabalhando em agência de propaganda, não estava feliz e precisava de desafios. Foi quando conheci Abrão para fazer um trabalho para um cliente. O trabalho não aconteceu mas montamos uma empresa que atendesse 
nossas ansiedades: uma escola de cinema e uma produtora para atender o mercado de propaganda. Concorrendo com bitolas profissionais achamos o nosso nicho: filmes para pré-testes, lançamento de produtos e filmes de treinamento. O Centro Cultural nasceu da junção da escola com a produtora. Daí os encontros com palestras de profissionais da área, sessões de cinema aos sábados a noite, exposições de experimentos com artistas plásticos, como Cinemóbile, Expo 73, fotos como de Otavio Roth.

O GRIFE - Grupo de Realizadores de Filmes Experimentais - foi além das expectativas, foi um marco que possibilitou o surgimento de profissionais hoje conceituados no Brasil (diretores de novela, teatro, cinema entre outros). Desmitificou a linguagem do cinema. Depois de mais de 40 anos, o GRIFE ainda é lembrado e respeitado. Pena que Abrão Berman não esteja aqui para receber aplausos.

Rafael Cruz: Toda mudança em formato de produção leva tempo para ser assimilada, principalmente pelo mercado. O GRIFE atuou também como produtor de filmes publicitários na nova bitola, justamente no momento de maior efervescência de sua novidade. Como foi a aceitação das agências? Quais foram as vantagens neste formato de produção? Conte-nos sobre algum caso de produção marcante em sua passagem pelo GRIFE.

Malu Alencar: $\bigcirc$ Super $8 \mathrm{~mm}$ era uma bitola considerada amadora, não tinha laboratório de copiagem e o som era outro problema. Mas logo no início da empresa, conhecemos um senhor que nos trouxe um projetor de filmes Super $8 \mathrm{~mm}$, que mudaria toda nossa história. Era uma maleta Fairchild que pesava em torno de 7 quilos, aberta se transformava numa televisão; o filme era colocado num cartucho - antecessor do VHS - fácil manuseio, foi um achado. Com essa maleta ganhamos o mercado de agências propaganda e clientes. O Super $8 \mathrm{~mm}$ foi utilizado como um "rough" dos storyboards, só que produzido em filme, lançamento de produtos, foi utilizado em vitrines de lojas com o filme rodando como se fosse uma televisão de fato. Antes da Kodak montar o laboratório de copiagem, fazíamos nossas cópias colocando o filme original no cartucho e através de um cone de papelão preto na tela conectando com a câmera, fazíamos 20, 30, 50 cópias! Mas os clientes não tinham idéia como fazíamos e nem poderiam saber.

Foi assim que fizemos o lançamento de "Potros e Potrancas" para Jockey Clube via Delta Propaganda, documentário dos 50 anos da Olivetti no Brasil, lançamento dos brinquedos Estrela; pré-teste para filmes comerciais para Omo,Fraldas Johnson, Band-Aid, Halls, Mentholiptus, Arno, Cinquentenário da GM do Brasil, lançamento de aviões da Embraer, entre outros.

Rafael Cruz: Em determinado momento o GRIFE, em sua sede, aliava a formação técnica na nova bitola com uma vasta programação que envolvia muitas outras linguagens artísticas, como as artes plásticas. Qual era a proposta do GRIFE em criar um ponto de encontro e fluxo de ideias em distintas expressões culturais? Qual foi a contribuição do diálogo estabelecido entre o vídeo e as demais linguagens?

Malu Alencar: Desde o início, em 1972, o GRIFE se tornou um ponto de encontro, a cidade estava carente de um lugar onde se pudesse discutir arte e cultura livremente, não podemos nos esquecer que montamos a empresa durante a ditadura militar. Por 
sermos uma escola e por trabalharmos com uma bitola considerada amadora a censura não se interessou muito pelo que fazíamos, mas quando começamos com os Festivais de Cinema em 1973, a censura esteve presente. Eu era responsável por acompanhar Dra. Solange (censora) para ver todos os filmes inscritos. Muita saia justa para liberar filmes e explicar que não eram subversivos.

Muitos artistas se inscreveram no curso de cinema para conhecer uma nova linguagem que misturava som, imagem, movimentos. Foi assim com o Cinemóbile e com a EXPO 73.

Nassessõesdesábadopassávamos filmes que haviam sido proibidos pela censura, tínhamos um acordo com algumas distribuidoras que nos cediam ou alugavam. $\bigcirc$ mesmo com filmes experimentais, desenhos animados como os de Norman MacLaren.

Organizamos também palestras com cineastas e intelectuais, entre eles: Jean Claude Bernadet e Mario Chamie.

Rafael Cruz: Em que momento específico o Super 8 entrou em sua fase de decadência? E como o GRIFE conviveu com esse processo?

Malu Alencar: No final de 1975 tivemos contato com o video-tape. O que seria essa "bitola" que não precisava de laboratório para revelação? Abrão não se interessou em conhecer, como ele era responsável pela parte técnica, fiquei de mãos amarradas. Quando em agosto de 1976 fui convidada para montar a produtora na TV Globo, tentei convencê-lo, mas ele foi irredutível. Sai do GRIFE em busca de novos desafios, foi graças ao conhecimento que tive com o Super 8mm que me possibilitou entender as dificuldades do video e com o apoio de profissionais, principalmente da área de fotografia e iluminação, o video logo conquistou espaço entre agências de propaganda e seus clientes.

No final de 70 Abrão montou cursos em VT, mas no inicio de 80 encerrou as atividades do GRIFE.

Rafael Cruz: A História Cultural considera a experiência histórica e humana, levando em conta o cotidiano como rico contexto de registro historiográfico. Um cartão postal, uma carta de amor, uma fotografia, tudo passa a ter seu valor simbólico reconhecido como registro de um pensamento, de uma forma de vida, de um grupo social. 0 Super $8 \mathrm{~mm}$ adentrou a esfera privada da vida social e produziu inúmeros registros familiares. Como historiadora, qual é sua avaliação sobre o encontro das novas tecnologias - assim como foi o Super 8 em seu tempo - com o cotidiano, nos pontos que se distanciam da dita "história oficial"? Que tipo de registro produzido em Super 8 você considera mais interessante?

Malu Alencar: Com o advento da fotografia em 1825/26 o registro do cotidiano ficou mais fácil. A fotografia foi a grande aliada da memória por perpetuar momentos, pessoas, monumentos, fatos. Uma relíquia. Com o advento do cinema, em 1895, varios formatos foram criados: $8 \mathrm{~mm}$, $16 \mathrm{~mm}, 35 \mathrm{~mm}, 70 \mathrm{~mm}$ e com o cinema a inauguração da conhecida "sétima arte".

Registrei vários depoimentos de personagens que entrevistei a partir de 1992, em Campos do Jordão, interior paulista. $\bigcirc$ que mais me impressionou foi de Heinz Boehme, tripulante de um navio alemão que aportou no porto de Santos em 1939 fugindo dos ingleses. Heinz tinha vários filmes em $8 \mathrm{~mm}$ registrando suas escaladas com amigos nas montanhas da Alemanha, na divisa com a República 
Checa; e de sua família, parentes e amigos, na Alemanha antes da Segunda Guerra Mundial. Era seu maior tesouro, a única coisa que o ligava ao seu passado. Confirmou a importância do registro de fatos e pessoas.

O Super $8 \mathrm{~mm}$ possibilitou perpetuar esses momentos de maneira muito mais intensa no âmbito familiar comoregistrodemomentosinesquecíveis como: casamentos, passeios, festas de crianças, comemorações, tudo com som, movimento e cor. Essa é a grande glória do Super $8 \mathrm{~mm}$.
[MALU DE ALENCAR]

Bacharel em História pela FFLCH/USP e cursou Propaganda e Marketing na ESPM. Trabalhou como Relações Públicas e Redatora até a fundação do GRIFE. Entre 1976 e 1978 foi Gerente do Departamento de Produção de Comerciais em VT da TV Globo; entre 1980 e 1982 Diretora Comercial da GLOBOTEC; e entre 1978 e 1989, Gerente do Departamento de Produção de Comerciais em VT da TV Gazeta/ Fundação Cásper Líbero. Em 1992 coordenou o Museu da Imagem e do Som de Campos do Jordão (MHIS).

Produziu os documentários "Shoko Suzuki" (1973) e "Aukre Kaiapó" (1990); o longa "Iracema, uma transa amazônica", de Jorge Bodansky (1976). Foi responsável pela realização do documentário "Windhuk, a 13ª viagem" (2004), sobre a prisão de alemães nos campos de concentração de 1942 à 1945 nas cidades de Guaratinguetá e Pindamonhangaba no Vale do Paraíba paulista.

No mercado publicitário produziu para Johnson
\& Johnson, General Motors, Wolkswagen, Nestlé, Arno, Gessy Lever, Embraer, Omo, Volvo, Ford, Cobal, Fisiba, Crefisul, Jóquei Clube de São Paulo, Avibrás, Rhodia, Volkswagen, Sendas, Tintas Coral, Santista, Pão de Açúcar, Casas Bahia, Fiat, Nestlé, Mc Donald's, Colgate Palmolive e Kibon.

Atualmente é conselheira da TV ASSIM (Associação de Imagens), organização não-governamental de radiodifusão comunitária e educativa, sediada na Vila Mariana, capital paulista.

\section{[RAFAEL CRUZ]}

Doutorando em Ciências Sociais pela Universidad de Buenos Aires. Atualmente é Relações Internacionais do Centro de Estudos LatinoAmericanos sobre Cultura e Comunicação da Escola de Comunicações e Artes da Universidade de São Paulo, Pesquisador do Ministerio de Cultura de la Nación Argentina e Coordenador do Sistema Municipal de Indicadores e Informações Culturais (SMIIC) de São José dos Campos/SP, na Fundação Cultural Cassiano Ricardo. Nesta mesma fundação é Conselheiro Deliberativo e Conselheiro-Gestor reeleito do Fundo Municipal de Cultura. 


\section{REFERÊNCIAS BIBLIOGRÁFICAS}

ROCHA, Flávio Rogério. Super Festivais do GRIFE: produção, circulação e formação de cineastas no Super8 brasileiro (1973-1983). São Carlos, 2015. 277p. Dissertação (Mestrado) - Programa de Pós-Graduação em Imagem e Som - PPGIS, Universidade Federal de São Carlos, 2015.

CINEMOBILE, nova forma de usar o cinema, O. Folha de São Paulo. Folha Ilustrada. São Paulo, 19 de abril de 1974, s/p.

KODAK.Super 8 mm products. Disponível em <http://motion.kodak.com/US/en/motion/ Products/Production/Spotlight_on_Super_8/Super_8mm_Products/index.htm>. Acesso em 25 de jun. de 2016. 